Tesis. Año 12, 11(12), 31-50

\title{
La otredad existencial en la cuentística de Julio Ramón Ribeyro
}

\author{
Ronald Antenor Espinoza Aguilar \\ ronald.unmsm314@gmail.com
}

\section{Resumen}

La crítica influenciada por la filosofía marxista y otras tendencias filosóficas ha direccionado el estudio de la narrativa corta ribeyriana hacia aspectos como la marginalidad y el escepticismo. Podría decirse que una obra, aparentemente simple y sencilla como la narrativa corta de Julio Ramón Ribeyro contiene en realidad un universo ficcional complejo que no puede ser abordado desde una sola mirada, pues eso nos conduciría solo a ver en los personajes ribeyrianos calcos y copias de clases sociales explotadas o seres grotescos e ilusos dentro de un sistema social injusto. En discordancia con las perspectivas anteriores, planteamos que, si bien el problema de la mímesis está profundamente enraizado en la cuentística ribeyriana y se hace visible a la distancia, no son en su mayoría los problemas sociales o los problemas cognoscitivos los que angustian a sus personajes, sino los problemas existenciales.

Palabras clave: Julio Ramón Ribeyro, mímesis, marginalidad, escepticismo, otredad, existencialismo.

\begin{abstract}
The criticism influenced by marxist philosophy, as well as criticism influenced by other philosophical tendencies, have directed the study of short ribeyrian narrative towards aspects such as marginality and skepticism. It could be said that a work, apparently, simple and simple, like Ribeyro's short narrative, actually contains a complex fictional universe that can not be tackled unilaterally from a single glance, since that would only lead us to see in the ribeyrian characters traces and copies of exploited social classes or grotesque and deluded beings within an unjust social system. In disagreement with the previous perspectives, we propose that, although the problem of mimesis is deeply rooted in the ribeyrian storybook and becomes visible at a distance, it is not mainly social problems or cognitive problems that truly anguish his characters, but the existential problems.
\end{abstract}

Keywords: Julio Ramón Ribeyro, mimesis, marginality, skepticism, otherness, existentialism. 


\section{La otredad existencial en la cuentística de Julio Ramón Ribeyro}

La crítica influenciada por la filosofía marxista —en la cual destacan Miguel Gutiérrez (1988) con La Generación del 50: un mundo dividido, James Higgins (1991) con Cambio social y constantes humanas: la narrativa corta de Ribeyro y Eva Valero (2001) con La ciudad en la obra de Julio Ramón Ribeyro-, y la filosofía posestructuralista — en la cual sobresalen Giovanna Minardi (2002) con La cuentística de Julio Ramón Ribeyro y Paul Baudry (2016) con "Tres respuestas a una modernidad en crisis y algunas posturas escépticas, estoicas y cínicas en la obra de Julio Ramón Ribeyro"-, así como la crítica influenciada por otras tendencias filosóficas, han direccionado el estudio de la narrativa corta ribeyriana hacia aspectos como la marginalidad y el escepticismo. Con acertada razón, casi la totalidad de la crítica ha resaltado el carácter mimético y realista de la narrativa corta de Ribeyro. Para agilizar la lectura, no mencionaremos a todos los estudiosos y críticos. No obstante, diremos que, en general, afirman que la obra narrativa (cuentística) de nuestro escritor refleja, representa, registra, testimonia, describe, retrata, muestra o capta la postración de la clase media, las condiciones de vida de los sectores marginales, la migración del campo a la ciudad, la explosión demográfica en Lima, los problemas de la modernidad, el contexto sociohistórico peruano de mediados del siglo XX, los problemas de la formación social, las contradicciones de su sociedad y de su época, los procesos sociales y políticos más complejos, la condición humana del hombre contemporáneo y la realidad social.

Según esta perspectiva - grosso modo - los personajes ribeyrianos solo son seres excluidos y segregados socialmente que confunden continuamente la ilusión con la realidad; hecho que los conduce al fracaso, entendido este como un fenómeno opuesto al éxito social en la mentalidad capitalista. Sin embargo, luego de un análisis fáctico de toda su narrativa corta, podemos afirmar que el autor de La tentación del fracaso no reconfiguró estéticamente en su casi centenar de cuentos ni al proletariado ni al campesinado, tampoco a la gran masa de migrantes andinos llegados en sucesivas oleadas y en grandes cantidades a 
la ciudad de Lima. El migrante andino casi no aparece en su obra cuentística, y las pocas veces que lo hace, por ejemplo, en "El sargento Canchuca", "La piel del indio no cuesta caro" o "Los otros", es presentado sin discurso propio y sin voz (a diferencia del personaje autóctono peruano de "El chaco", que esgrime un discurso rebelde en un contexto rural). En consecuencia, casi tampoco aparece en su narrativa corta la nueva clase media emergente, sino única y reiteradamente, la vieja clase media aristocrática limeña en decadencia o la antigua pequeña burguesía pauperizada.

Una obra, aparentemente simple y sencilla como la narrativa corta de Ribeyro contiene en realidad un universo ficcional complejo que no puede ser abordado desde una sola mirada, pues eso nos conduciría solo a ver en los personajes ribeyrianos calcos y copias de clases sociales explotadas o seres grotescos e ilusos dentro de un sistema social injusto. $\mathrm{Y}$ en este universo, no solo es injusto el sistema social, sino también el mundo, la vida y el destino.

En discordancia con las perspectivas anteriores, planteamos que si bien el problema de la mímesis está profundamente enraizado en la cuentística ribeyriana y se hace visible a la distancia, no son en su mayoría los problemas sociales o los problemas cognoscitivos los que angustian de verdad a sus personajes, sino los problemas existenciales.

En contraste con las visiones unilaterales, proponemos aquí la confluencia multilateral de varias teorías para explicarnos mejor el universo otro ficcional ribeyriano, en que los "otros" y la "otredad existencial" son el centro del argumento literario y el centro de la historia humana. Un aparato metodológico y categorial proveniente de la teoría de la otredad, la teoría marxista, la escuela subalterna, el posestructuralismo filosófico y literario, así como la corriente filosófica existencialista, nos permitirán tener esta visión planteada.

Es cierto que la otredad no es aún una teoría unificada, sino una teoría en formación, cuyos pilares pululan dispersos en Ser y tiempo (1927) de Martín Heidegger, El ser y la nada (1943) de Jean-Paul Sartre, Yo-tú (1969) de Martin Buber, los escritos de Mijaíl Bajtín Yo también soy (2000), La buella del otro (2000) de Emmanuel Levinas, Si mismo como otro (1996) de Paul Ricoeur y las obras de Jacques Lacan. Estos pensadores han contribuido con una serie de conceptos e ideas que destacamos con nombre propio: la coexistencia heideggeriana (la necesidad de convivir con los demás para sentirnos seres humanos), la mirada sartreana (la propuesta de que todos somos un ser-para-otro, vivimos sometidos al escrutinio de la opinión pública), la exotopía bajtiniana (según la cual todos los hombres son otros fuera de nuestra mismidad), la participación leviniana (el planteamiento de que el sujeto se acerca a los demás, pero no se libera nunca de la soledad ontológica), la ipseidad ricoeuriana (la propuesta de que la identidad personal en movimiento alcanza su máxima 
tensión cuando se relaciona con la alteridad del otro) y la especularidad lacaniana (hipótesis que sugiere que el ser humano — ve- reflejado a su "otro semejante" en el espejo).

Nosotros hemos intentado sistematizar estas propuestas en una teoría unificada de la otredad, esbozando sus rasgos más generales en una tesis próxima a publicarse, titulada La otredad en la obra cuentística de Julio Ramón Ribeyro. En ella señalamos que los seres humanos se dividen en idénticos y otros, de acuerdo a la dimensión de la realidad en que se desenvuelven y según su relación con el poder hegemónico.

En la dimensión económica social, la identidad predominante es establecida por la sociedad oficial que detenta los medios de producción y a la cual pertenecen no solo la clase burguesa o la terrateniente, sino también sus acólitos más cercanos: la clase media citadina acomodada y la aristocracia provinciana. Estos crean y hegemonizan los cánones que rigen a la identidad clasista dominante. Los demás grupos excluidos del poder, los subalternos — bloque que conforma al pueblo, en que se encuentra la gran masa de segregados, explotados, dominados y marginados: vendedores ambulantes, desempleados, recicladores, artesanos, campesinos pobres, obreros, pescadores, prostitutas, etcétera- que forman la periferia política, son los otros. Es decir, los diferentes económico sociales, los sin poder y sin dinero, los que no cumplen con los cánones sociales del éxito y los estándares de la sociedad oficial, los condenados a una economía de supervivencia, cuya vida se desenvuelve en el mundo de abajo, en la sociedad otra.

En la dimensión cultural, la identidad predominante es establecida también por la sociedad oficial cuya ideología política hegemónica establece los cánones y los estándares culturales, espaciales (geocéntricos) y antropológicos (raciales) de la sociedad. Así, para la sociedad hegemónica oficial serán idénticos todos aquellos que se desenvuelven dentro de la influencia de la cultura europea, el espacio occidental (Europa y Norteamérica) y pertenecen a la raza blanca. En cambio, las culturas oceánicas, orientales, africanas o latinoamericanas y las razas amarilla, negra o cobriza, pertenecen a los otros culturales, espaciales o antropológicos. Estos son diferentes en el mundo oficial occidental por su idioma, sus creencias, el color de su piel o el continente de su procedencia.

En la dimensión existencial, la identidad predominante es una vez más establecida por la sociedad oficial cuya concepción del mundo hegemónica dicta los parámetros fundamentales de vida: el éxito social (salud, dinero y amor), el liberalismo ético, el relativismo axiológico (pragmatismo), la estética utilitarista y la teleología irracionalista (el fin último de la vida es el paraíso o la nada; ambos, lugares inexistentes en la realidad). Así, para la sociedad hegemónica oficial, serán idénticos todos aquellos que se desenvuelvan en estos parámetros 
filosóficos. En cambio, todos los que "fracasen", no se sientan "libres" o no ansíen la vida eterna, pertenecen a los otros, a los diferentes por su concepción del mundo.

Para Walter Mignolo (2003), en Historias locales/diseños globales, los excluidos económicamente, los segregados racialmente y los hombres de pensamientos divergentes al de la sociedad oficial, pertenecerían al mundo otro. La otredad, en este sentido, ya no se reduciría a la alteridad —al otro como prójimo o al otro que no soy yo-, sino que formaría todo un universo con un pensamiento, una geopolítica y una cultura otra.

Ahora, centrándonos en nuestro autor, este se sumergió en todas las dimensiones mencionadas intentando aprehender las diferentes otredades, pero muy en especial, las de carácter existencial y en ese proceso — en su periplo por la cruda realidad- descubrió los diversos mecanismos de otrificación a los que son sometidos los seres humanos para ser convertidos en otros: la deshumanización (que implica la cosificación, la instrumentalización y la animalización), la alienación y la enajenación. Así, configuró a sus personajes en su universo ficcional como seres otros. Así tenemos relatos que abordan la dimensión económica social, en que se evidencia la deshumanización. De estos destacan "Interior L" y "La tela de araña" como ejemplos de cosificación e instrumentalización, en que los protagonistas son concebidos como simples objetos e instrumentos de placer; y como ejemplos de animalización, "Los gallinazos sin plumas" y "Los cautivos", en que los personajes principales son equiparados a las aves, ya sea por el contexto de la miseria en que se desenvuelven (los gallinazos en los basurales) o por el cautiverio en el cual se encuentran (en jaulas). En general, en esta dimensión, los personajes ribeyrianos viven aplastados y subyugados de manera cruel por el determinismo económico del cual no logran liberarse pese a que se rebelan contra él, como en "Al pie del acantilado", o sutilmente, en "La estación del diablo amarillo".

En la dimensión cultural, en cambio, los personajes de Ribeyro sufren el peso alienante de las ideologías que estereotipan a los hombres según su raza, idioma o procedencia espacial. Esto está plasmado claramente en relatos como "Alienación", "De color modesto", "La piel del indio no cuesta caro", "Los moribundos", "El sargento Canchuca", "El chaco" y "Los eucaliptos".

Por último, en la dimensión existencial, los personajes ribeyrianos viven presos del azar, el eterno retorno o el fracaso, los cuales se ensañan con la libertad y la felicidad de los seres humanos, no permitiéndoles una existencia libre y trascendente, sino encadenándolos a una vida monótona y mediocre, en un contexto irracional dominado por el pesimismo, el nihilismo y el absurdo. Estos elementos están plasmados, por ejemplo, en "Silvio en El Rosedal", "El ropero, los viejos y la muerte", "Nada que hacer monsieur Baruch", "Los merengues", "E1 
próximo mes me nivelo", etcétera. Como demostraremos, esta última dimensión fue el núcleo fundamental sobre la cual giró la narrativa corta de Ribeyro.

A fines de la década de 1940 (el "siglo del horror") — cuando nuestro autor empieza a escribir sus primeros cuentos- y a mediados de la década de 1950 - periodo en que se publica su primer libro de relatos Los gallinazos sin plumas (1955) - , aún se sentía en el mundo el desasosiego por las consecuencias de las dos guerras mundiales. Ese horror se plasmó no solo en el arte a través del expresionismo, sino que también se instaló con más fuerza el pesimismo en la concepción filosófica del mundo de la sociedad contemporánea. Este pesimismo fue sistematizado por la corriente filosófica existencialista.

El existencialismo - una corriente filosófica y literaria irracionalista, que con el neopositivismo seudorracionalista constituían las dos tendencias fundamentales de la filosofía del siglo XX opuestas al marxismo- tiene sus raíces en la filosofía irracionalista y la literatura existencial de la segunda mitad del siglo XIX y las dos primeras décadas del siglo pasado, en la cual destacan precursoramente algunos filósofos como Søren Kierkegaard, Arthur Schopenhauer y Friedrich Nietzsche y literatos como Fiódor Dostoievski (Crimen y castigo, 1866), Miguel de Unamuno (Niebla, 1914) y Franz Kafka (La metamorfosis, 1915). Alcanzó su máximo apogeo en el llamado "periodo de entre guerras" con Martin Heidegger, Karl Jaspers y Gabriel Marcel, y su periodo culminante en el proceso mismo y luego de la segunda gran conflagración mundial con JeanPaul Sartre (El ser y la nada, 1943) y Albert Camus (La peste, 1947).

Es probable que el existencialismo, que influyó notablemente en la literatura de la época - sobre todo en el teatro del absurdo de Eugène Ionesco ( $\mathrm{La}$ cantante calva, 1950) y de Samuel Becket (Esperando a Godot, 1952), así como las obras de Adamov, Genet, Hesse, Pavese y otros- haya influido también en la Generación del 50 y en especial en Ribeyro. Wáshington Delgado (1995), en “Julio Ramón Ribeyro en la Generación del 50", y Miguel Gutiérrez (1988), en La Generación del 50: un mundo dividido, reconocen la influencia del existencialismo no solo en gran parte de los escritores de esta generación (Carlos Eduardo Zavaleta, Enrique Congrains, Sebastián Salazar Bondy, Oswaldo Reynoso, etcétera), sino, sobre todo, en Ribeyro.

A pesar de que nuestro escritor nunca se declaró personalmente como un "escritor existencialista", se hallan varias referencias de lecturas, autores y temas existencialistas en su diario personal, La tentación del fracaso. Así, en ese escrito autobiográfico, menciona su "complacencia morbosa por las situaciones límite" (tomo II, p. 22, 14 de abril de 1961) y realiza una reflexión acerca del significado del absurdo: "Quizá el mundo no sea absurdo —en el sentido de Camus, un absurdo que significa un orden, es decir, una predestinación con signo negativosino simplemente incongruente" (tomo II, p. 88, 1964). También alude a su 
intención de "continuar escribiendo mi novela camusiana" (tomo II, p. 23, 28 de octubre de 1951) o a sus lecturas filosóficas: "Leyendo a Platón" (tomo II, p. 179, 15 de abril de 1973); "He leído las últimas páginas de la Ética de Spinoza" (tomo I, p. 44, 13 de marzo de 1954); "Leo a Sartre" (tomo I, p. 126, 14 de abril de 1961). Por último, a lo largo de las páginas de este diario, cita el nombre de algunos filósofos o escritores de tendencia irracionalista: Nietzsche, Heidegger, Kafka, Pavese, Hesse, Becket.

Al parecer no sería una casualidad que de sus 98 relatos, 55 aborden fundamentalmente la dimensión existencial de la otredad. Asimismo, la mayoría de sus cuentos siguen una estructura filosófica existencialista constante: situación límite - crisis existencial - salida; esta última casi siempre desemboca en la angustia, el fracaso o el absurdo. Los personajes ribeyrianos se enfrentan constantemente a una situación paradójica o ilógica — por ejemplo, la dicotomía ilusión-realidad - conduce al hastío, la náusea, el fracaso existencial o el nihilismo.

También se hallan —expresa o tácitamente- en sus cuentos una considerable cantidad de términos y conceptos existencialistas: el hastío, en "La molicie"; la nada, en "El ropero, los viejos y la muerte"; el absurdo, en "Silvio en El Rosedal"; la angustia, en "Nada que hacer monsieur Baruch"; la coexistencia heideggeriana, en "Tristes querellas en la vieja quinta"; la mirada sartreana, en "Una aventura nocturna"; la especularidad lacaniana, en "El profesor suplente"; la participación leviniana, en "La primera nevada”, etcétera.

De la misma manera, se hallan elementos generales de una concepción irracionalista del mundo - afines al existencialismo - en la cuentística y en la obra ribeyriana: una visión pesimista y azarosa de la historia en "Las cosas andan mal Carmelo Rosa" y en las Cartas a Juan Antonio; una concepción cíclica del tiempo (el eterno retorno) en "El carrusel"; una tendencia cognoscitiva escéptica en "Conversación en el parque".

Todas estas consideraciones nos permiten aseverar que hubo un gran acercamiento de la narrativa corta de Ribeyro a una concepción existencialista del mundo. Y si a estas consideraciones le agregamos la profunda preocupación de este escritor limeño por aprehender y reconfigurar literariamente la otredad existencial en su cuentos; entonces, la perspectiva ribeyriana del mundo se encuadra más dentro del irracionalismo que dentro de la literatura de denuncia (o protesta) de raigambre marxista o de la burda literatura burguesa que exalta principalmente lo grotesco. Si bien el marxismo y el escepticismo aparecen de una forma clara en algunos cuentos de Ribeyro, en la mayoría de ellos se revela esencialmente una atmósfera existencial. 
En consonancia con lo anterior, es evidente que el centro de la cuentística ribeyriana lo ocupa el ser humano y sus vicisitudes existenciales más que las contradicciones ideológicas o las luchas políticas. Esta aseveración es corroborada por varios críticos. Así, Wolfgang A. Luchting (1971), en Julio Ramón Ribeyro y sus dobles, afirma que el humanismo de Ribeyro es propio de una sociedad en decadencia (p. 147). Giovanna Minardi (2002), en La cuentística de Julio Ramón Ribeyro, lo califica como un humanismo comprensivo y corrosivo a la vez (p. 26). Peter Elmore (2002), en su libro El perfil de la palabra. La obra de Julio Ramón Ribeyro, nos da a entender que es un humanismo liberal ajeno a los totalitarismos modernos, pero sobre todo es un humanismo existencialista (un humanismo con ética del existencialismo) (p. 53). Del mismo modo, Paul Baudry (2016), en "Tres respuestas a una modernidad en crisis: algunas posturas escépticas y cínicas en la obra de Julio Ramón Ribeyro”, niega que el humanismo ribeyriano sea de izquierda (p. 202).

Resulta claro que la profunda preocupación de Ribeyro por el ser humano — su afán por colocar al hombre en el centro de su narrativa corta en particular y su obra literaria en general- y su posición al margen de la historia concreta de la sociedad, desechan tanto la tesis de la consolidación de un humanismo ribeyriano de derecha (liberal) o la de un humanismo ribeyriano de izquierda y cede paso a la tesis de un humanismo existencialista.

Luego de un estudio completo y holístico de la narrativa corta ribeyriana podemos decir que nuestro escritor evidenció y aprehendió la otredad existencial en:

1) El carácter ontológico de la persona. El humano puede captarse a sí mismo o ser captado como un ser trascendente (valioso) o una res nullius (un objeto sin valor); también como un ser que se desenvuelve en la soledad ontológica o en la coexistencia.

2) La temporalidad del ser humano. La persona puede captarse o ser captada como un ser temporal cuya existencia termina en cualquier momento. El hombre es un ente sometido a la inexorabilidad del tiempo y acechado a cada instante por la muerte. Aquí se evidencia la idea de Heidegger: el hombre es un ser-para-la-muerte.

3) Lo absurdo de la existencia. El ser humano puede captarse o ser captado como un ente que vive en un mundo paradójico o sin sentido, en un lugar en donde no puede realizarse plenamente a causa de sus limitaciones racionales. Lo irracional le produce desazón al hombre. Según Jean-Paul Sartre, los medios para acceder al absurdo son el hastío, la náusea y la angustia.

4) La conciencia de la libertad. El hombre puede captarse en su ser — para — sí o ser captado en su ser — para— otro. Aparentemente, en el 
contexto individual, el ser humano goza de una libertad ilimitada, pero esta se ve recortada por los demás (por los prójimos idénticos - los alter- o los otros, los diferentes) en el contexto social. Esta contradicción le resulta absurda e injusta y le permite comprender al hombre su esencia como ser humano o como ser en general.

Todos estos rasgos de la otredad existencial aparecen indistintamente en los 55 cuentos de Ribeyro catalogados por nosotros como "existencialistas". Resulta obvio que por razones de espacio no podemos abordar esa cantidad de relatos aquí, sin embargo, intentaremos demostrar lo dicho remitiéndonos a cinco de sus cuentos donde aparecen - en los personajes, en el discurso y la voz de estos- conceptos existencialistas fundamentales: la coexistencia heideggeriana, la mirada sartreana, el fracaso existencial, el absurdo y la nada.

El primer concepto mencionado (la coexistencia heideggeriana) se evidencia en "Tristes querellas en una vieja quinta". Este es un cuento realista cuyo narrador heterodiegético describe a través de un estilo directo/indirecto y una focalización variable, un cronotopo que representa de modo principal la dimensión existencial de la otredad.

El narrador configura a dos personajes protagonistas — el viejo, solitario y solterón Memo García y doña Francisca Morales una anciana morena, gorda y enana- en un contexto alienado por la complejidad de la convivencia humana.

Luego de haber visto la transformación de una Lima cada vez menos virreinal, más bulliciosa y caótica, Memo siente que, junto a su vieja quinta, también él está envejeciendo. No esperaba nada de la vida, ningún suceso que cambiase su predestinada soledad hasta que todo cambió con la llegada de doña Pancha.

Bastó una sola mirada para sentir que se odiarían. Desde entonces, se pasaban la mayor parte del tiempo entre insultos, discusiones y denigrándose mutuamente. No obstante, un día, la anciana viuda enfermó y luego falleció. Producto de esto, Memo García se quedó otra vez en la soledad absoluta.

En este contexto, los mecanismos de otrificación ocurren de dos modos: 1) de manera horizontal, desde Memo García hacia Francisca Morales y viceversa; 2) de forma interiorizada; es decir, en la mismidad del viejo solitario. En el primer caso, ambos se otrifican por medio del racismo; él le dice: "zamba grosera», "zamba sin educación»; ella le responde: "cholo malcriado", "cholo indecente". Del mismo modo, ambos se deshumanizan mutuamente a través de la animalización: "Este no es un corral para traer animales. Y a usted, ¿cómo lo han dejado entrar en la quinta? Animal será usted, una verdadera bestia para decirlo en una palabra. Más bruta que su loro" (Ribeyro, 2010, p. 578). 
En el segundo caso, la soledad que se deriva de la muerte y la ausencia definitiva de doña Francisca no solo enfrenta a Memo García a una situación límite sino que también lo sumerge en una crisis existencial, pues comprende que la vida en soledad es dolorosa; la convivencia con el otro resulta ser - en muchos casos - conflictiva, tortuosa; pero necesaria a la vez. Así, se hace evidente la importancia de la coexistencia heideggeriana, en el sentido de que el hombre necesita de los demás para sentirse humano, tal como queda evidenciado en el siguiente fragmento:

Heredó el loro en su jaula colorada y terminó, como era de esperar, regando las macetas de doña Pancha, cada mañana, religiosamente, mientras entre dientes la seguía insultando, no porque lo había fastidiado durante tantos años, sino porque lo había dejado, en la vida, es decir, puesto que ahora formaba parte de sus sueños. (Ribeyro, p. 586)

Acerca de este cuento Jorge Coaguila (2008) dice: "Tristes querellas en la vieja quinta" "refiere sobre la convivencia, la necesidad del otro" (p. 96). E1 discurso y la voz de ambos personajes refleja la necesidad de la compañía humana, incluso cuando esta se exprese en los hechos más nimios de la vida. La coexistencia - o la convivencia - no elimina la soledad ontológica, pero hace más llevadera la vida.

Esta última idea parece ser también la conclusión pedagógica en "La primera nevada" cuando un poeta solitario - dueño de un departamento en $\mathrm{Pa}$ rís - echa a la calle a su amigo Torroba (un poeta vagabundo y marginal) por gorrero y vividor, sin embargo, se arrepiente de su accionar, pues comprende que se ha quedado solo otra vez y es incapaz de vivir en soledad; por ello, le suplica que vuelva:

Cuando atravesó el bulevar rumbo al barrio árabe, sentí que me ahogaba en esa habitación que me parecía, ahora, demasiado grande y abrigada para cobijar mi soledad. Abriendo la ventana de un manotazo, saqué medio cuerpo fuera de la baranda:

— Torroba! — grité-. ¡Torroba, estoy aquí! ¡Estoy en mi cuarto! (Ribeyro, p. 419)

Por otro lado, la mirada sartreana se evidencia notable y completamente en "El profesor suplente". Este es un cuento realista en el cual un narrador heterodiegético describe, por medio de una combinación de estilos indirecto/directo y una focalización variable - un cronotopo que representa de modo fundamental la dimensión existencial de la otredad.

E1 narrador configura a un personaje principal otro — el cobrador Matías Palomino - en un contexto marginalizado por la pobreza económica y la mediocridad. Matías es recomendado por un amigo suyo, el doctor Valencia, para 
ocupar una plaza vacante como profesor de historia en una escuela. Muy animado y optimista, cree que por fin le ha llegado el merecido reconocimiento a su valía y su capacidad intelectual. Motivado por esta oportunidad, se dedica con ahínco a preparar su lección. Al día siguiente se presenta a las inmediaciones del colegio decido a asumir su nuevo cargo y dictar sus clases con éxito. Pero en su camino halla una serie de obstáculos imaginarios y pretextos para no presentarse como el nuevo profesor de historia. Acobardado por estos hechos y la incomprensible situación, se retira y llega derrotado a su casa donde le esperaba su mujer ilusionada con su nuevo cargo.

En este contexto, los mecanismos de otrificación solo ocurren en la mismidad del propio personaje protagonista. Este es un personaje alienado que tiene una falsa conciencia de sí mismo, la cual lo enajena, le hace comportarse de una forma distinta y errada a la que realmente es. Él se cree una persona inteligente, valiosa y capaz; pero en la realidad es un simple iluso, mediocre y timorato que presume de lo que no es.

Dos factores importantes intervienen en estas circunstancias para que este personaje acceda a la esencia de sí mismo; es decir, a su condición de ser otro:

1) La mirada sartreana, el escrutamiento social al que es sometido el individuo:

Al divisar la verja asumió el aire profundo y atareado de un hombre de negocios. Se disponía a cruzarla cuando, al levantar la vista, distinguió al lado del portero a un cónclave de hombres canosos y ensotanados que lo espiaban, inquietos. Esta inesperada composición —que le recordó a los jurados de su infancia- fue suficiente para desatar una profusión de reflejos de defensa y, virando con rapidez, se escapó hacia la avenida. (Ribeyro, p. 249)

2) La especularidad lacaniana, el escrutamiento al que se somete el propio individuo a través de su imagen reflejada en el espejo:

Se disponía a regresar [...] cuando detrás de la vidriera de una tienda de discos distinguió a un hombre pálido que lo espiaba. Con sorpresa constató que ese hombre no era otra cosa que su propio reflejo. Observándose con disimulo, hizo un guiño, como para disipar esa expresión un poco lóbrega que la mala noche de estudio y de café había grabado en sus facciones. Pero la expresión, lejos de desaparecer, desplegó nuevos signos y Matías comprobó que su calva convalecía tristemente entre los mechones de las sienes y que su bigote caía sobre sus labios con un gesto de absoluto vencimiento. (p. 247)

Matías Palomino, al confrontar su personalidad alienada y enajenada con la realidad y al descubrir su verdadero ser, se enfrenta a una situación límite que lo deja atónito y lo introduce en lo incomprensible, en lo absurdo. Sumido en una 
profunda crisis existencial, vaga de regreso a casa, lugar donde acepta —en los brazos de su esposa- su condición de hombre mediocre y fracasado; su condición de "otro". El profesor suplente no halla una salida a esa crisis existencial y se refugia en el llanto y el desconsuelo. El discurso y la voz del otro son casi inconsistentes por su falsedad ideológica y su marginalidad frente al poder de la sociedad. Ambos elementos de la otredad, en este caso, son deslegitimados por la mediocridad e ineptitud del personaje.

En otros cuentos como "Una aventura nocturna", "Los merengues" y "De color modesto" también se registra un intenso protagonismo de la mirada sartreana en la dinámica del desenvolvimiento del personaje. Tanto Arístides como Perico y Alfredo fracasan en su parca rebeldía contra los cánones impuestos en la realidad para preservar el orden social. La libertad individual de todos ellos se ve avasallada por la cruel opinión colectiva, la misma que los empuja con cierta violencia y crudeza a seguir las normas y los estándares ya establecidos. Los tres personajes mencionados se convierten en pobres objetos frente a un sujeto poderoso y superior: la sociedad premunida de su valoración axiológica hegemónica. Esta induce a todos los personajes protagonistas al fracaso: Arístides no obtiene el amor deseado el cual es solamente una mera ilusión; Perico se ve privado de los deliciosos merengues porque la sociedad considera que un pobre como él no puede tener dinero para esos manjares. Por su parte, Alfredo no puede abandonar el molde ideológico establecido de antemano para los grupos sociales, la sociedad considera que un blanco no puede relacionarse sentimentalmente con una negra.

El fracaso existencial se evidencia de manera notable en "El próximo mes me nivelo". Este es un cuento realista cuyo narrador heterodiegético describe a través de un estilo directo/indirecto y una focalización variable, un cronotopo que representa de modo fundamental la dimensión existencial de la otredad.

El narrador configura a un personaje principal - Alberto, una especie de peleador justiciero citadino - en un contexto alienado por el convencionalismo social del machismo matonesco y el racismo, pero también deshumanizado por la animalización, la violencia y la pobreza.

En este relato, los mecanismos de otrificación se manifiestan de dos modos: 1) de manera vertical descendente, secundaria y casi imperceptiblemente, desde la sociedad hegemónica hacia los subalternos (representado por los personajes marginales); 2) principalmente, en la mismidad del personaje protagonista (Alberto). En el primer caso, el sistema imperante aliena a los individuos por medio de convencionalismos sociales; básicamente, el del machismo matonesco. La sociedad hegemónica hace creer a muchos varones que el reconocimiento puede alcanzarse por medio de la fuerza y el maltrato a los débiles. Por medio del convencionalismo de la postergación, intenta ocultar las limitaciones de 
un grupo en la jerarquía social, en la cual sus integrantes se pasan casi toda la vida justificando sus fracasos y colocando vanamente todas sus esperanzas en el mero transcurrir del tiempo. Por otro lado, el sistema social también aliena a los individuos a través del racismo. La existencia del Cholo Gálvez en una ciudad indica la presencia de personas otrificadas mediante el racismo. Este cliché (de "Cholo") tan arraigado en nuestra sociedad denota una otrificación. Incluso, el mismo Alberto deshumaniza al Cholo Gálvez a través de la animalización: "Seguramente que así de duro, de pura bestia, había arrebatado al negro Mundo y al sargento Mendoza, en Surquillo, el cetro de los matones" (p. 532). Pero no son estas otredades de las dimensiones social y cultural las que prevalecen en este relato, sino la existencial.

En el segundo caso, Alberto logra percibir la otredad cultural a la que es sometido (el convencionalismo matonesco) a través de la mirada sartreana: "Al distinguir la rueda de los mirones tuvo conciencia de que estaba cautivo, literalmente, en un círculo vicioso" (p. 533). Esto quiere decir que él valía como ser humano solo por sus dotes de peleador callejero. Pero no es solamente esa mirada la que le permite adquirir la conciencia de su mismidad, de su ipseidad — de su identidad en movimiento- sino la consciencia de su otredad económica, social y cultural, las que le permiten, en última instancia, acceder a su otredad existencial al final del cuento:

Estirando la mano hacia la mesa de noche buscó la jarra de agua, pero solo halló la libretita donde hacía sus cuentas. Algo dijo su mamá desde la otra habitación, algo del horno, de la comida.

—Sí — murmuró Alberto sin soltar la libreta—. Sí, el próximo mes me nivelo.

Llevándose la mano al hígado, abrió la boca sedienta, hundió la cabeza en la almohada y se escupió por entero, esta vez sí, definitivamente, escupió su persona, sus proezas, su pelea, la postrera, perdida. (p. 536)

Alberto, en ese instante, enfrenta una situación límite al mezclarse y colisionar en su mente su pasado de peleador callejero, su presente cargado de cuentas y su futuro incierto. Luego de esa crisis existencial comprende que no ganará la batalla de la vida, que toda lucha en general es vana, absurda. Ahora sabe que es un ser angustiado por la nada.

Sandra Granados Vidal (2014), en "Una mirada crítica a la producción literaria de Julio Ramón Ribeyro a partir de sus documentos autobiográficos”, interpreta el fracaso no como un fenómeno ligado al éxito económico social, principalmente, sino como un fenómeno existencial relacionado con la trascendencia vital del ser humano. Creemos que es el sentido que predomina en la 
mayoría de los cuentos de Ribeyro; entre los que podemos citar, por ejemplo, a "Ausente por tiempo indefinido", "Solo para fumadores" y "Los otros".

En el primer relato, Mario se rinde ante la magnitud de la evidencia de la coexistencia heideggeriana y renuncia a la literatura cuando comprende que él no puede vivir aislado, ensimismado en la actividad creativa literaria, porque es un ser que necesita de los demás seres humanos; acepta que la vida es válida por sí misma y que hay belleza en el simple hecho de vivirla. Elige, entonces, la identidad social impuesta: la de saberse un ser común en la comunidad de los hombres. Desecha la posibilidad de convertirse en un otro aislado, marginal y acepta estoicamente su fracaso existencial, el abandono de su deseo de convertirse en un escritor.

En el segundo relato, Ribeyro (como personaje) descubre que tanto la vida como el acto de fumar son absurdos. Sabe que ambos fenómenos algún día tendrán un final. Ya que el tabaquismo - o cualquier otra cosa- lo conducirán inexorablemente a la muerte; en este sentido, intenta justificar mediante argumentos hedonísticos su fracaso existencial como ser precario en el mundo: declara su atención hacia la sutil belleza estética de los cigarrillos y al placer que le causa el acto de fumar. Sabe que toda existencia en su intento por perdurar es un vil fracaso y no le queda nada más que disfrutar del placer como una miserable moneda de consuelo.

En el tercer relato, la existencia de Martha (una niña de familia inmigrante judía), el Cholo Paco y Ramiro (un poeta huraño) se ve truncada por el azar. Así, el fracaso existencial se hace mucho más evidente: es una fuerza sobrenatural o un designio que se le impone - casi siempre injustamente- a los hombres y sobre la cual estos no tienen injerencia alguna. Los tres personajes mueren a una corta edad, de la manera más sorpresiva e impredecible: sus vidas son un fracaso evidente y palpable de la existencia humana.

El absurdo se evidencia de manera notable en "Silvio en El Rosedal". Este es un cuento realista cuyo narrador heterodiegético describe - por medio de un estilo indirecto y una focalización cero- un cronotopo que representa de modo principal la dimensión existencial de la otredad.

El narrador configura a un personaje principal otro —el viejo solterón, solitario, marginal y escéptico Silvio Lombardi, "un hombre sin iniciativa ni pasión"- en un contexto social alienado por los convencionalismos y en un contexto personal alienado por la reflexión filosófica compulsiva. Luego de una vida oscura como ayudante de ferretero, Silvio Lombardi, hereda una hacienda en Tarma, llamada El Rosedal. Hasta entonces, Silvio, era un hombre solitario, sin amigos ni novia, aislado de la sociedad doblemente (pese a sus raíces italianas, no pertenecía a la élite de esa colonia; tampoco al mundo 
andino peruano). Su vida transcurría sin objetivos, ni metas y horizontes claros, pues: "Luego de algunas escapadas juveniles y nocturnas por la ciudad, buscando algo que no sabía lo que era y que por ello mismo nunca encontró y que despertaron en él cierto gusto por la soledad, la indagación y el sueño" ( $\mathrm{p}$. 648). Un día (a los 40 años de edad), ya instalado en la hacienda, se da cuenta de que su vida transcurre sin ningún sentido: "Una mañana que se afeitaba creyó notar el origen de su malestar: estaba envejeciendo en una casa baldía, solitario, sin haber hecho realmente nada, aparte de durar". (pp. 652-653). La búsqueda de una salida racional para esa crisis existencial tarda muchos años, en los cuales se orienta hacia la música (el violín), la adquisición de cosas materiales a través de la ganadería (el comercio); la reflexión filosófica y por último al amor platónico. Pero en el transcurso de su vida se cansa y decepciona de cada una de estas salidas: abandona tácitamente el mantenimiento y administración de su hacienda; luego de dar un concierto con un músico genial - Rómulo Cárdenas-y después de varias sesiones musicales deja a un lado el violín; agotado intelectualmente en su afán obsesivo por descubrir el verdadero sentido de la palabra RES y por medio de la reflexión filosófica —a través de la cual descubre el principio del orden, el SER, el infinito, el absurdo y la nada- la hace a un lado; decepcionado del amor platónico que siente hacia la hija de su prima - la bella quinceañera Roxana Elena Setembrini- porque esta coquetea con los jóvenes en la fiesta de su cumpleaños, también abandona el interés por ese sentimiento.

En este contexto, los mecanismos de otrificación ocurren de cuatro modos: 1) de manera vertical descendente, imperceptiblemente, desde la sociedad hegemónica (representada en la voz del narrador) hacia los andinos; 2) de manera vertical ascendente, desde los peruanos aborígenes otros hacia la élite (representada por Silvio); 3) de manera vertical descendente, desde las élites italianas acomodadas y los hacendados tarmeños hacia Silvio y viceversa); 4) de manera interna (en la mismidad del personaje protagonista). En el primer caso, los peruanos andinos son otrificados y deshumanizados por medio de lo grotesco, por ejemplo al: "Obligar a Basilia Pumari a que se pusiese delantaly toca al servir, lo que arruinó su belleza nativa y la convirtió en un mamarracho colosal" (p. 666). En el segundo caso, los peruanos autóctonos subalternos otrifican a Silvio a través del convencionalismo del poder: "Para la sociedad indígena, era una especie de inmigrante sin abolengo ni poder" (p. 648); y también por medio de las diferencias culturales: "Los Pumari no podían entender cómo este par de señores se olvidaban hasta de comer para frotar un arco contra unas cuerdas produciendo un sonido que, para ellos, no los hacia vibrar como un huaino" (p. 661).

En el tercer caso, las élites citadinas otrifican a Silvio por su condición económica social: "Para la rica colonia italiana, metida en la banca y en la 
industria era el hijo de un oscuro ferretero" (p. 648). En cambio, los hacendados tarmeños lo otrifican por su origen: "Los tarmeños lo acogieron al comienzo con mucha reticencia. No solo no era del lugar, sino que sus padres eran italianos, es decir, doblemente extranjero" (p. 651). Del mismo modo, Silvio otrifica a las hijas de los hacendados tarmeños por su fealdad: "Silvio se dio cuenta de que estaba circunscrito por solteronas, primas, hijas, sobrinas, o ahijadas de hacendados, feísimas todas, que le hacían descaradamente la corte" (p. 651).

En el cuarto caso, Silvio capta su propia otredad mediante la reflexión filosófica compulsiva cuando intenta hallar una explicación racional a cada acto de su vida. Cabe destacar que a diferencia de otros personajes de otros cuentos de Ribeyro, cuando Silvio enfrenta sucesivas situaciones límites, no recurre a soluciones irracionales como la venganza, el suicidio o el fracaso inevitable; sino a la abstracción filosófica. Así como Funes el memorioso de Borges no puede dejar de recordar; Silvio no puede dejar de filosofar. Por lo general, cada acto de su vida lo conduce hacia la especulación metafísica; por ejemplo, el acto de la contemplación del jardín de E1 Rosedal lo lleva a descubrir el principio del orden: "Era realmente extraño, nunca imaginó que en ese abigarrado rosedal existiera en verdad un orden" (654); ese principio lo remite a la categoría RES (cosa); la inversión de ese término a la palabra SER (que engloba a la totalidad de lo existente) y esta lo deriva al todo. El intento de encajar el todo en el SER lo conduce a la incongruencia: "Soy excesivamente rico", "Serás enterrado rápido", "Sábado entrante reparar", "sólo ensayando regresarás", "Sócrates envejeciendo rejuveneció", "Sirio engendró Rocío". Es decir: "Las frases que se podían componer a partir de esas letras eran infinitas" (p. 658). Posteriormente descubre que RES en catalán significaba "nada": "Durante varios días vivió secuestrado por esta palabra, vivía en su interior escrutándola por todos lados, sin encontrar en ella más que lo evidente: la negación del ser, la vacuidad, la ausencia” (p. 662). Esto implicaba que él también era parte de esa "nada": "Él ya sabía que nada era él, nada el rosedal, nada sus tierras, nada el mundo". (662-663). Silvio intenta hallarle un sentido (lógico racional) a la vida, pero en cada suceso descubre que ni aquella ni el mundo lo tienen. David Raymundo Chong Lam (1999) dice al respecto: "El tema del cuento se resume en que toda búsqueda del sentido de la vida es una quimera" (p. 651).

Silvio capta su propia otredad cuando percibe que es un ser que ha sido arrojado a un mundo sin sentido, ilógico, absurdo; entonces comprende que de su identidad de hombre racional se deriva un otro, un ente irracional: ha hallado en sí mismo el límite de la razón. Solo entonces abandona su incesante búsqueda. James Higgins (1991) dice al respecto: "Silvio se reconcilia con la vida abandonando la vana búsqueda de un significado y aceptando su aparente 
falta de propósito [...], se da cuenta de que la vida no necesita tener sentido para ser soportable" (p. 166).

El discurso y la voz escépticas de Silvio hacen que la dimensión existencial sea el que más resalte en este relato y, por ende, se convierta en el aspecto fundamental del cuento. La duda se involucra en casi todos los actos del personaje protagonista y se inocula de modo sutil en la totalidad del universo representado, relegando las dimensiones económica, social y cultural a un plano secundario. Ambos elementos - discurso y voz- le permiten a Silvio encontrar su propia otredad, a trascender su propia ipseidad (su identidad en movimiento).

Cabe resaltar que este es el relato donde mejor se evidencie la otredad existencial de un personaje. Sus vicisitudes, sus meditaciones por el sentido de la vida siempre terminan por crearle un conflicto existencial y lo sumen en la nada que al fin y al cabo es SER (Silvio en El Rosedal).

Si lo absurdo es un hecho contrario a la razón, lo sinsentido, lo incongruente, lo ilógico, lo desprovisto que nos acerca a la angustia metafísica; entonces esa es también la materia en torno a la cual giran cuentos como "La insignia", "El marqués y los gavilanes" y "Nada que hacer monsieur Baruch", solo por citar los más representativos.

En "La insignia", el protagonista es invadido por una sensación de lo absurdo en el inicio, en el proceso y en el final del relato. Todos los hechos acaecidos allí no tienen sentido y no guardan correlación entre ellos, estos son realizados por el personaje principal sin ningún objetivo ni razón de ser. En "El marqués y los gavilanes", el protagonista — don Diego - termina recluido en su casa. Abrumado por la dolorosa realidad, la paranoia, los delirios y la demencia, este termina sus días sumergido en el tiempo circular —el eterno retorno-, en una labor banal y absurda de escribir repetidamente un mismo fragmento: "En el año de gracia de mil quinientos cuarenta y siete, el día cinco de septiembre, en la ciudad de Valladolid, vio la luz don [...]. Y así continuó, sin que nadie pudiera arrancarlo de su escritorio, durante el resto de su vida" (Ribeyro, p. 641).

En "Nada que hacer, monsieur Baruch", el protagonista —un sexagenario judío lituano - cansado de la soledad que lo aísla del mundo, decide suicidarse efectuándose un corte profundo en la garganta. Luego de un lapso de divagaciones se convence de que la muerte es tan absurda como la vida misma y se arrepiente de su acto, pero este ya es un proceso irreversible. Aún moribundo hace todo lo posible para salvarse, empero se da cuenta de que el azar ha puesto todo en contra de su deseo súbito e inesperado por aferrarse a la vida; las personas y los objetos que podían haberlo ayudado o salvado están demasiado lejos de su alcance. 
Por último, la nada se evidencia notablemente en "El ropero, los viejos y la muerte". Este es un relato realista, en el cual un narrador homodiegético describe, por medio de un estilo directo y una focalización interna, un cronotopo que representa de modo fundamental la dimensión existencial de la otredad.

El narrador personaje configura a un personaje consciente de su otredad don Perico, su padre, un hombre cuyas "Lecturas [...] lo hacían meditar sobre el sentido de nuestra existencia" (p. 540)-, en un contexto alienado por los recuerdos y el pasado. Este último poseía un ropero antiquísimo en cuyo espejo se habían contemplado los más insignes antepasados de su familia: congresistas, ministros y rectores. Dicho mueble poseía un gran valor sentimental para él; pues el espejo lo ubicaba casi en el mismo tiempo y espacio con sus abuelos, pero todo esto cambió cuando el hijo de su amigo Alberto Rikets - llamado Albertito- quiebra el espejo del ropero, totémico y genealógico, con un balón de fútbol.

En este contexto, los mecanismos de otrificación solo ocurren de manera interiorizada (en la mismidad del personaje protagonista, don Perico). Este alienado en un primer momento por el pasado, que no le permite reconocerse tal como es y lo induce a una falsa conciencia de sí mismo- accede a la esencia de su propio ser cuando es destruido el espejo del ropero: al absurdo y la nada. Esto está expresamente considerado en el texto: "Sabía que [...] ya no necesitaba del espejo para reunirse con sus abuelos, no en otra vida, porque él era un descreído, sino en este mundo que ya lo subyugaba, como antes los libros y las flores: el de la nada" (p. 543). El pelotazo destruye simbólicamente su pasado y lo enfrenta a una situación límite — polarización pasado/presente- la misma que a su vez lo sume en una crisis existencial, de la cual logra salir a través del nihilismo, del descubrimiento de su verdadero ser: el hecho de configurarse como un ser-para-la-muerte. Don Perico descubre que es un otro absurdo en un mundo convencional, superficial, banal.

E1 discurso existencialista y la voz nihilista de don Perico - estructurada y representada por el narrador personaje- se convierte en una muestra del escepticismo imperante en el sistema social, escepticismo que se desplaza hacia una estación más radical: el nihilismo, el convencimiento de que la vida, la existencia y el mundo son absurdos. Ambos elementos evidencian aún más la configuración de un pensamiento otro evasivo de la realidad.

De esta manera, con las pruebas esgrimidas y los argumentos esbozados, creemos que al menos queda demostrada la tendencia existencial — si bien aún no el carácter existencialista - de la narrativa corta ribeyriana que, para la mayoría de la crítica, se circunscribe en la marginalidad social y el escepticismo como visión predominante del mundo. No obstante, como ha quedado demostrado, la crítica no le ha dado una mirada distinta a su cuentística, la cual a 
pesar de haber sido estudiada desde distintas ópticas aún sigue siendo un texto abierto para los estudios posteriores.

\section{Referencias}

Ribeyro, J. (2010). La palabra del mudo. (Edición definitiva). Madrid: Seix Barral.

- (1992). La tentación del fracaso I. Diario personal. 1950-1960. Lima: Jaime Campodónico.

—. (1993). La tentación del fracaso II. Diario personal. 1960-1974. Lima: Jaime Campodónico.

-. (1996). Cartas a Juan Antonio. 53/58. Tomo I. Lima: Jaime Campodónico.

-. (1998). Cartas a Juan Antonio. 58/70. Tomo II. Lima: Jaime Campodónico.

Baudry, P. (2014). Tres respuestas a una modernidad en crisis: algunas posturas escépticas y cínicas en la obra de Julio Ramón Ribeyro. Boletín del Instituto RivaAgüero. Núm. 37. Lima.

Bajtín, M. (1991). Teoría y estética de la novela. Madrid: Taurus.

Buber, M. (1969). Yo y tú. Buenos Aires: Nueva Visión.

Bubnova, T. (2000). Yo también soy (fragmentos sobre el otro). Mijail Bajtín. México: Taurus.

Coaguila, J. (2008). Ribeyro, la palabra inmortal. Iquitos: Tierra Nueva Editores.

Chong, D. (1999). El hombre según Julio Ramón Ribeyro. Pamplona: Universidad de Navarra.

Delgado, W. (1996). Julio Ramón Ribeyro en la Generación del 50. En: Julio Ramón Ribeyro: el rumor de la vida. Lima: Arteidea, 109-119.

Elmore, P. (2002). El perfil de la palabra. La obra de Julio Ramón Ribeyro. Lima: Fondo Editorial de la Pontificia Universidad Católica del Perú.

Granados, S. (2014). Una mirada crítica a la producción literaria de Julio Ramón Ribeyro a partir de sus documentos autobiográficos. Flores Heredia, G., Morales Mena, J. y Martos Carrera, M. (editores). Ribeyro por tiempo indefinido, Congreso Internacional. Lima: Ediciones Cátedra Vallejo, 155-172.

Gutierrez, M. (1988). La Generación del 50: un mundo dividido. Lima: Labrusa.

Higgins, J.(1991). Cambio social y constantes humanas. La narrativa corta de Ribeyro. Lima: Fondo Editorial de la Pontificia Universidad Católica del Perú.

Luchting, W. (1971). Julio Ramón Ribeyro y sus dobles. Lima: Instituto Nacional de Cultura.

Mignolo, W. (2003). Historias locales/diseños globales. Colonialidad, conocimientos subalternos y pensamiento fronterizo. Madrid: Akal. 
Minardi, G. (2002). La cuentística de Julio Ramón Ribeyro. Lima: Banco Central de Reserva del Perú-La Casa de Cartón.

Ricoeur, P. (1996). Si mismo como otro. Madrid: Siglo Veintiuno.

Sartre, J-P. (1996). El ser y la nada. Buenos Aires: Losada.

Valero, E. (2001). La ciudad en la obra de Julio Ramón Ribeyro. Alicante: Universidad de Alicante. 